Gut, 1962, 3, 252

\title{
Chronic painless pancreatitis
}

\author{
S. J. M. GOULSTON AND N. D. GALLAGHER \\ From the Gastroenterology Unit, Royal Prince Alfred Hospital, Sydney, Australia
}

EDITORIAL SYNOPSIS This paper describes four patients whose chief symptoms were steatorrhoea and loss of weight. Despite the absence of a history of abdominal pain investigations showed that these patients had chronic pancreatitis, which responded to medical treatment. The pathological findings in two of these cases and in six which came to necropsy are reported.

Pain is the outstanding symptom of pancreatitis in all its stages. The pain is usually severe, situated in the upper abdomen and may radiate to the back. Less typical attacks of pain may also occur. However, the post-mortem demonstration of acute pancreatitis in patients without a recorded history of pain by Evans, Gross, and Baggenstoss (1958) suggests that pain may be completely absent. A history of pain may also be absent in patients with chronic pancreatitis and although this was recognized by Friedreich (1878) and Opie (1902), its recognition to-day followed the paper by Bartholomew and Comfort (1956) describing the clinical features of 10 patients. Our interest in this condition resulted from the discovery of four patients with chronic painless pancreatitis who were in a group of 35 patients with chronic pancreatitis admitted to this hospital in 1959 and 1960. A study of post-mortem records from the period 1950 to 1960 revealed six patients in whom the diagnosis of chronic painless pancreatitis was not considered during life in view of the absence of any symptoms or signs suggestive of pancreatic disease. Our experience is reported in this paper.

The four living patients were men in the sixth or seventh decades who complained of fatty diarrhoea and weight loss. Diarrhoea was the most distressing symptom and had been present for periods ranging from four months to six years. Two patients had lost more than $50 \mathrm{lb}$. in weight but loss of weight was less marked in the remainder. No members of the group complained of a loss of appetite, appetite being either unchanged or increased during the period of illness. Clinical evidence of diabetes mellitus was found in only one patient but the remaining three patients had pre-diabetic glucose tolerance tests. There was no history of episodes of abdominal pain nor was there a history suggestive of biliary disease. The intake of alcohol by the four patients was insignificant.

Steatorrhoea was shown to be present by the finding of abnormal values for faecal fat excretion and in two patients faecal fat excretion exceeded $100 \mathrm{~g}$. per day. The results of ${ }^{131} \mathrm{I}$-labelled triolein and oleic acid tests indicated pancreatic steatorrhoea. Plain $x$-ray examination of the abdomen revealed pancreatic calcification in only one patient. Malabsorption states such as idiopathic steatorrhoea and Whipple's disease were excluded by the findings of normal jejunal mucosa after intestinal biopsies were performed or normal values for the urinary excretion of an oral dose of D-xylose. Local lesions of the intestine such as stricture and diverticulosis were not demonstrated by radiological studies. Laparotomy was necessary in two patients in whom symptoms had been present for four and 12 months respectively to exclude carcinoma of the pancreas or duct of Wirsung. Pancreatic tissue obtained by biopsy showed that although the outline of the pancreatic lobules and their ducts remained intact, exocrine cells were almost completely absent (Fig. 1) and were replaced by discrete collections of lymphocytes and plasma cells, neutrophils being conspicuously absent (Fig. 2). Pancreatic fibrosis was marked and was both perilobular and intralobular. Some islets of Langerhans were preserved and vascular changes were minor. The case history of one of these patients is as follows.

\section{CASE HISTORY}

A male engineer, married and aged 62, was admitted to hospital in August 1960 with complaints of diarrhoea and weight loss. The diarrhoea had begun abruptly four months previously and after a short time the stools appeared fatty. Despite a good appetite he had lost $21 \mathrm{lb}$. in weight. He had been in good health until these 


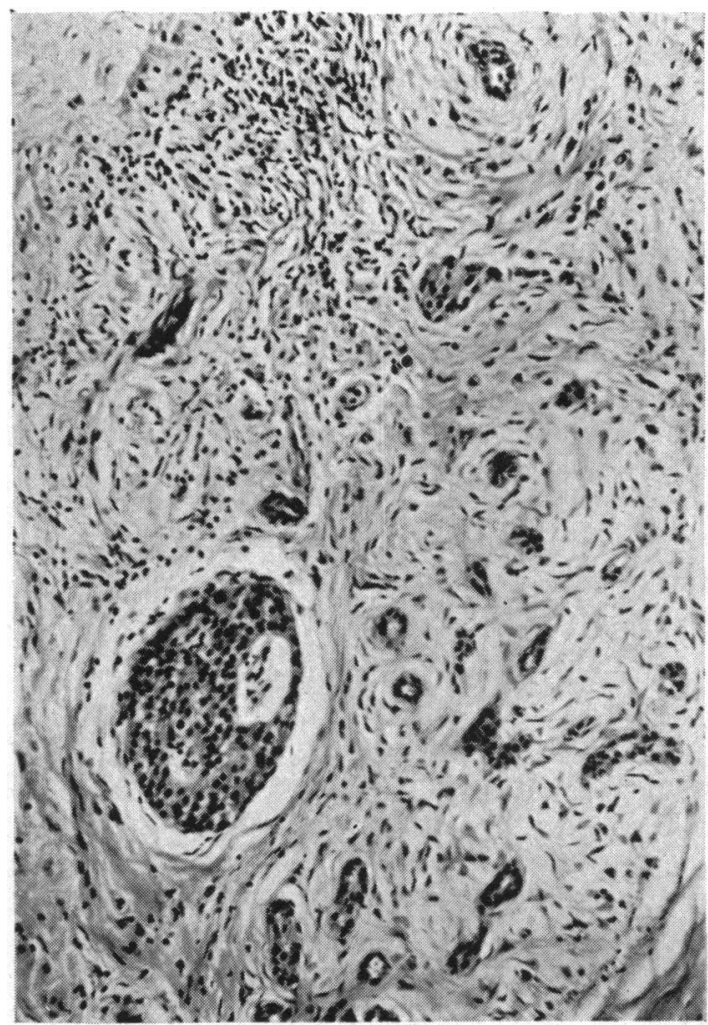

FIG. 1. Pancreatic biopsy material showing disappearance of exocrine tissue and pancreatic ducts surrounded by whorls of fibrous tissue (haematoxylin and eosin $\times 125$ ).

symptoms appeared and had had no serious illnesses. Drinking and smoking were confined to social occasions.

He was moderately obese and apart from the presence of bilateral inguinal herniae there were no other physical abnormalities. The systolic blood pressure was $120 \mathrm{~mm}$., the diastolic pressure $80 \mathrm{~mm}$., and urine on analysis was normal. Anaemia was not present and serum electrolyte values, including serum calcium and phosphorus, were normal. Liver function tests and the serum protein pattern were also normal. Serum amylase concentrations were less than $100 \mathrm{mg}$. of glucose per $100 \mathrm{ml}$. of serum on three occasions. A glucose tolerance test showed a fasting blood sugar level of $97 \mathrm{mg}$. per $100 \mathrm{ml}$., and values of $115,150,150$, and $132 \mathrm{mg}$. per $100 \mathrm{ml}$. were obtained at 30-minute intervals. Mild glycosuria was detected during this period but ketone bodies were not found. The faecal fat excretion was $47 \mathrm{~g}$. per day and the urinary excretion of D-xylose after an oral dose of $25 \mathrm{~g}$. was $7.7 \mathrm{~g}$. in five hours. Of the ingested dose of ${ }^{131}$ I-labelled triolein $12 \%$ was found in the stools after 48 hours and $2 \%$ of the ingested dose was found after a dose of ${ }^{131}$ I-labelled oleic acid. A series of radiographs of the small bowel revealed increased transit times and in some areas there was a tendency to flocculation of the medium. 6

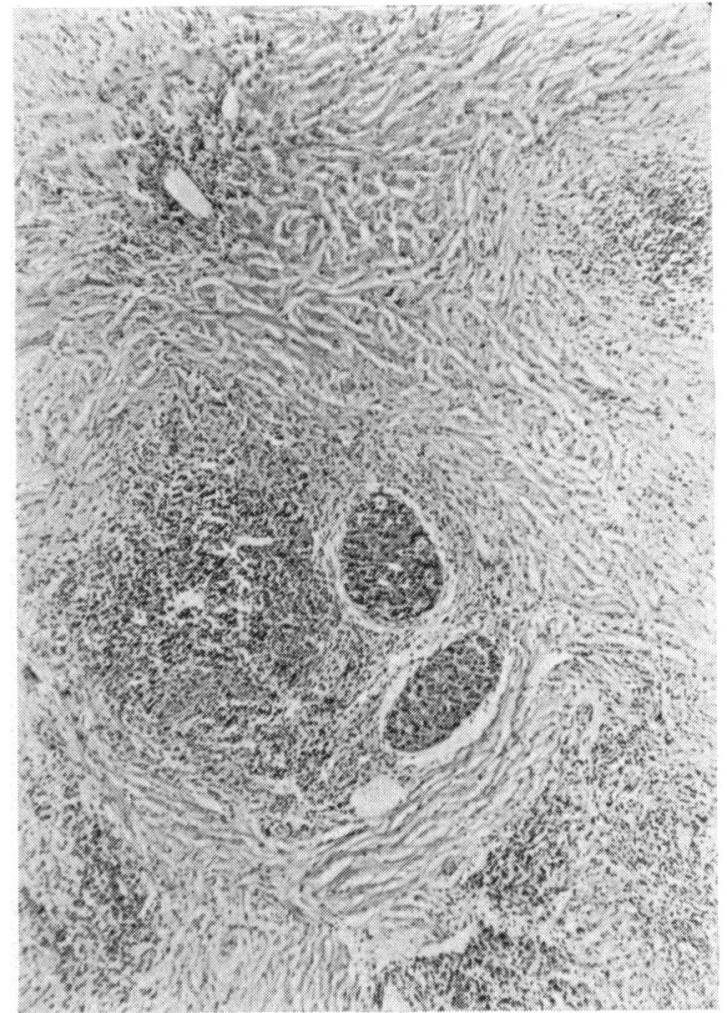

FIG. 2. Focal collections of lymphocytes and plasma cells and surviving islets of Langerhans (haematoxylin and eosin $\times 75)$.

A plain radiograph of the abdomen did not show any calcification. Laparotomy was necessary to determine the nature of the pancreatic lesion indicated by these studies. The pancreas was found to be small and indurated and a biopsy was taken. Examination of biopsy material confirmed the diagnosis of chronic pancreatitis.

Treatment since operation has consisted of a low-fat and high-protein and carbohydrate diet, together with pancreatic enzyme supplements. Marked improvement has occurred over a period of one year.

\section{DISCUSSION}

The clinical findings in our patients are similar to those reported by Bartholomew and Comfort (1956), by Maimon, Kirsner, and Palmer (1948), and by Mencer Martin (1954), and are grouped in Table $I$. Other authors, for example Boyer and Mackay (1960), have referred to this type of illness. The report of Bartholomew and Comfort indicates that these patients may have any combination of pancreatic steatorrhoea, diabetes mellitus, and pancreatic calcification, and loss of weight was a prominent 
TABLE I

CLINICAL FINDINGS IN 18 REPORTED CASES

\begin{tabular}{lccc} 
Author & Steatorrhoea & Diabetes & Calcification \\
\hline Maimon et al. (1948) & 3 & 2 & 3 \\
Mencer Martin (1954) & 1 & 1 & 1 \\
Bartholomew and Comfort & 10 & 7 & 8 \\
(1956) & 4 & 1 & 1
\end{tabular}

symptom in their patients. Moreover, they noted the presence of a pseudocyst in one patient and obstructive jaundice in another. These reports also indicate that both sexes may be affected and that the illness occurs predominantly in the sixth and seventh decades. The incidence of chronic painless pancreatitis is probably small, although Gross (1958) found four patients in a group of 75 patients with chronic pancreatitis and our incidence is also high.

The histopathology of the pancreatic tissue obtained from two patients showed marked pancreatic fibrosis; exocrine cells had disappeared and been replaced by collections of lymphocytes and fibrous tissue. Examination of post-mortem material from six other patients gave similar findings. Two of the latter group also had small areas of acute inflammation and fat necrosis. These examples offer further support for the occurrence of acute, subacute, and chronic pancreatitis unaccompanied by pain. Although in our material it was notable that the ducts were not dilated, the histological features do not allow a distinction to be made between chronic painless and chronic relapsing pancreatitis. Furthermore the appearances we have described are similar to those found by Bartholomew, Baggenstoss, Morlock, and Comfort (1959) in pancreatic atrophy and lipomatosis but the massive fatty infiltration which may be present in the latter condition was absent.

Numerous factors have been described in the aetiology of pancreatitis and these have recently been reviewed by Blumenthal and Probstein (1959). These include biliary tract disease, chronic alcoholism, protein malnutrition, pancreatic duct obstruction, hyperparathyroidism, and hyperlipaemia. Our experience did not suggest that any of these had a significant aetiological role nor was there a history of abdominal trauma, infective pancreatitis, or a family history of pancreatic disease. Whether chronic painless pancreatitis is the end-result of repeated episodes of silent acute pancreatitis or the result of an insidious chronic inflammatory process from the beginning is unknown. The latter process suggests the possibility of an auto-immune mechanism but the results of antigen-antibody studies in chronic pancreatitis are inconclusive (Murray and Thal, 1960). The role of vascular disease is also uncertain but attention was drawn to this possibility by our finding widespread hypertensive and degenerative vascular disease at necropsy in six patients. Joske (1955) has suggested that arterial disease may contribute to the development of chronic pancreatitis, and Blumenthal and Probstein (1959) report perilobular and intralobular fibrosis in the pancreas of patients with degenerative vascular disease in amounts increasing with age. However, much of the thought devoted to the origins of pancreatic disease remains speculative, and the reasons for the absence of pain in these patients are also unknown.

The treatment of chronic painless pancreatitis is entirely medical as the absence of pain removes the main indication for surgery. Our patients responded well to a high-protein and carbohydrate, low-fat diet, together with pancreatic enzyme supplements and vitamins. Although this régime helped in the control of diabetes mellitus in one patient, his insulin requirements remained high. Clinical evidence of diabetes has not appeared in the remainder during a followup period of one year. Our experience and that of Bartholomew and Comfort (1956) indicates that these patients have a satisfactory prognosis. Death due to vascular disease in our cases coming to necropsy suggests that a number may eventually die in this way.

We would like to acknowledge the help of Dr. V. J. McGovern with the pancreatic histology; Mr. F. Mills performed the laparotomies. The Gastroenterology Unit is supported by the Bushell Trust.

\section{REFERENCES}

Bartholomew, L. G., Baggenstoss, A. H., Morlock, C. G., and Comfort, M. W. (1959). Primary atrophy and lipomatosis of the pancreas. Gastroenterology, 36, 563-572.

- and Comfort, M. W. (1956). Chronic pancreatitis without pain. Ibid., 31, 727-743.

Blumenthal, H. T., and Probstein, J. G. (1959). Pancreatitis, pp. 15-63, 247. Springfield, Illinois: Thomas.

Boyer, J. T., and Mackay, I. R. (1960). The aetiology, course and surgical aspects of pancreatitis. A review of 108 cases. Aust. N.Z. J. Surg., 30, 150-157.

Evans, H. W., Gross, J. B., and Baggenstoss, A. H. (1958). Acute and subacute interstitial pancreatitis: A clinicopathologic study. Gastroenterology, 35, 457-464.

Friedreich, N. (1878). "Diseases of the Pancreas." In Cyclopaedia of the Practice of Medicine, ed. H. Ziemssen, Vol. 8, p. 551. Sampson Low, London.

Gross, J. B. (1958). Some recent developments pertaining to pan creatitis. Ann. intern. Med., 49, 796-819.

Joske, R. A. (1955). Aetiological factors in the pancreatitis syndrome. Brit. med. J., 2, 1477-1481.

Maimon, S. N., Kirsner, J. B., and Palmer, W. L. (1948). Chronic recurrent pancreatitis. Arch. intern. Med., 81, 56-72.

Martin, M. Mencer (1954). Pancreatic lithiasis. Diabetes mellitus. Pulmonary tuberculosis. Intermittent claudication. Proc. roy. Soc. Med., 47, 513-515.

Murray, M. J., and Thal, A. P. (1960). The clinical significance of circulating pancreatic antibodies. Ann. intern. Med., 53, 548-555.

Opie, E. L. (1902). The causes and varieties of chronic interstitial pancreatitis. Amer. J. med. Sci., 123, 845-868. 